\title{
EDUCAÇÃO AMBIENTAL CRÍTICA EM ESPAÇO NÃO FORMAL: MAPEAMENTO AMBIENTAL DA REGIÃO DE SÃO DOMINGOS NO MUNICÍPIO DE SUMARÉ/SP
}

\author{
Áurea Cristina Bastos da Costa Pereira ${ }^{1}$, Maria Guiomar Carneiro Tomazello ${ }^{2}$
}

\begin{abstract}
RESUMO
Este trabalho é resultante de uma pesquisa-ação participativa realizada em uma região de Sumaré/SP que congrega vários bairros de baixa renda, com os moradores vivendo em situação de risco. Por meio da construção de um mapeamento ambiental, discutiram-se questões do e no cotidiano com os adolescentes, moradores dessas localidades, atendidos por uma ONG local. O objetivo foi problematizar a realidade de forma a instrumentalizá-los para o enfrentamento dos problemas socioambientais, identificados no desenrolar da pesquisa, para que esses deixem de ser naturalizados por eles e passem a ser compreendidos como o produto de determinadas formas de organização social e considerados em seu contexto sócio-histórico.
\end{abstract}

Palavras-Chave: mapeamento ambiental; educação ambiental crítica, educação ambiental não formal; pesquisa-ação participativa

\section{ABSTRACT}

This work is the result of a participative research-action carried out in a region of Sumaré/SP which congregates several low-income neighborhoods, with the residents living in situations of risk. Through the construction of an environmental mapping, were discussed issues of the everyday life with adolescents, residents in these localities, attended by a local NGO. The objective was to problematize the reality in order to instrument them to face the environmental problems, identified in the course of the research, so they are no longer familiar to them and should be understood as the product of certain forms of social organization and considered in its socio-historical context.

Keywords: Environmental mapping; critical environmental education, environmental education, non-formal education

\section{INTRODUÇÃO}

Este trabalho é resultante de uma pesquisa-ação-participativa em nível de mestrado, realizada em uma região de Sumaré/SP em parceria com jovens atendidos pela Organização Não Governamental (ONG) Instituto Bem Querer IBQ (http://institutobemquerer.org.br/), que atua com populações vulneráveis na Região do CRAS (Centro de Referencia de Assistência Social) São Domingos, situada no entorno

\footnotetext{
${ }^{1}$ Licenciada em Biologia.

${ }^{2}$ Doutorado em Tecnologia Nuclear pela Universidade de São Paulo (1994). Professora do PPGE da Universidade Metodista de Piracicaba
} 
do Ribeirão Quilombo. A instituição tem como missão "promover a sustentabilidade comunitária por meio da educação básica, complementar e cultural, da assistência social e do exercício de seu papel cidadão, a fim de que sua ação protagonista a conduza à verdadeira melhoria da qualidade de vida". Essa ONG não é essencialmente ambientalista, mas tem projetos na área, além de trabalhos na área da saúde, alfabetização, artes, atendimento às crianças etc.

Desde os primeiros contatos com a ONG, observamos que poderia ser desenvolvido não só um projeto de pesquisa para fins de atendimento às normas do Mestrado em Educação, mas algo mais permanente que envolvesse funcionários da própria ONG, jovens e familiares da comunidade em seu entorno. Além de um trabalho mais contínuo, almejou-se desenvolver atividades no âmbito de uma educação ambiental crítica.

A tendência crítica, segundo Loureiro (2003) trabalha a partir da realidade cotidiana, visando à superação das relações de dominação e de exclusão que caracterizam e definem a sociedade contemporânea, ou seja, se desenvolve a luz de um referencial marxista, distinguindo-se das tendências conservadoras que dissociam o social do ambiental. "Não nos educamos abstratamente, mas na atividade humana coletiva, mediada pelo mundo (natureza), com sujeitos localizados histórica e espacialmente” (LOUREIRO, 2003:41).

Segundo Mészáros (2005), a educação, na perspectiva crítica, busca contribuir para a compreensão da realidade para a transformação, simultaneamente, da sociedade e da educação, no processo de formação humana. Marx não escreveu propriamente sobre o meio ambiente, mas tinha a compreensão de que os seres humanos fazem parte da natureza- que seria o seu corpo inorgânico. Em sua época não havia a publicização da questão ambiental, entretanto,

[...] é preciso reconhecer que em função do seu método, para o qual não há nada fora da natureza, estando esta em movimento contraditório de autoorganização, abordava os efeitos das relações sociais no processo de estranhamento da natureza, decorrente da expropriação material dos trabalhadores, e os efeitos nocivos no ambiente decorrentes do modo de produção capitalista e suas relações de dominação e coisificação da vida. (DUARTE, 1995; MÉDICI, 1983, apud LOUREIRO, 2007, p. 41).

Assim, o marxismo denuncia o caráter contraditório dos modos de produção capitalista, apontando caminhos para entender e superar a injustiça socioambiental. 
Meyer (1991) considera que o espaço construído inclui o mundo natural não como realidade autônoma, sem sujeito social. É por meio do trabalho que o ser humano vive e realiza sua existência, por meio das relações sociais. Para essa autora antes mesmo de aprendermos a ler observamos o ambiente, que seria a nossa primeira leitura do mundo, carregada de percepções, cujos significados vão se adquirindo ao longo do tempo por meio das relações sociais.

$\mathrm{O}$ fato de o ambiente estar em processo contínuo de mudanças, causadas tanto por causas naturais como por ações antrópicas, uma proposta pedagógica de educação ambiental, segundo Meyer (1991), tem que contemplar essas mudanças, a apropriação dos recursos naturais pelos diferentes grupos sociais, em função de fatores históricos, econômicos e culturais.

Outro ponto importante apontado por Meyer é quanto à situação ambiental das cidades e a naturalização dos problemas. $\mathrm{O}$ ambiente passa despercebido, pois as pessoas se acostumam a olhar e a conviver, sem refletir, sem questionar, como se aquela realidade fosse natural em vez de uma realidade socialmente construída. A nossa capacidade de observação, de registro, de indignação, fica adormecida diante do que nos parece natural. Podemos citar como exemplo a poluição dos rios que cruzam as cidades. Essa degradação ambiental é entendida como um produto "natural" do progresso.

A autora sugere então a construção de um mapeamento ambiental de forma a estimular um re-olhar, um re-descobrir e um des-vendar do ambiente em que vivemos e convivemos.

\footnotetext{
O mapeamento significa um inventário, um levantamento e um registro da situação ambiental do bairro e da cidade em seus múltiplos aspectos como: saneamento (água, esgoto e lixo), energia elétrica, transporte, tipos de moradia e materiais de construção, flora e fauna, recursos hídricos e minerais, indústria e comércio, organização social do trabalho, serviços de saúde, patrimônio histórico, artístico e arquitetônico, áreas de lazer agricultura, pecuária, hábitos alimentares e crenças. Enfim, inventariar as relações sociais que os seres humanos vão estabelecendo entre si e os demais seres vivos, quem se apropria e como se apropria dos elementos naturais (água, ar, terra, fogo), do céu, da flora e da fauna. (MEYER, 1991, p.43-44)
}

O mapeamento oportuniza o levantamento de dados da cotidianidade dos sujeitos da pesquisa, entendendo cotidianidade como "a dimensão mais imediata, o conjunto de atividades elementares para a realização de nossas necessidades biológicas e sociais", "pois sem cotidianidade não há mediação entre o micro e o macro, entre as 
mudanças locais e globais, não há concretização das transformações sociais", segundo Loureiro (2007, p.35) que, por sua vez, se apoia em conceitos presentes em obras de Lefebvre e Heller.

Mas para Spink (2007, p.7) é fundamental não só investigar o cotidiano, mas no cotidiano, pois ao pesquisarmos o cotidiano está instaurada a clássica separação entre pesquisador e seu objeto de pesquisa, mas, se pesquisarmos no cotidiano, "seremos partícipes dessas ações que se desenrolam em espaços de convivência mais ou menos públicos".

Partindo desses pressupostos teóricos, as questões de pesquisa foram:

- Quais os elementos mais significativos do meio ambiente, identificados por jovens que vivem em situações de risco e em ambiente degradados?

- Quais os novos olhares, questionamentos e conhecimentos produzidos pelos jovens durante o processo de elaboração do mapeamento?

O trabalho tem como objetivo a construção de um mapeamento ambiental de bairros atendidos pela ONG Instituto Bem Querer e, a partir dele, discutir coletivamente questões socioambientais com os jovens, moradores dessas localidades, em geral, vivendo em situação irregular, e que frequentam a ONG, de forma a construir a vida social, colocando-a em questão.

\section{CAMINHOS METODOLÓGICOS}

São várias as metodologias a serem aplicadas em pesquisas de educação ambiental, que variam de acordo com os objetivos, características dos projetos e também em função das concepções de educação ambiental, assumidas pelo pesquisador. Estas podem ser, de acordo com Tozoni-Reis (2008): i) disciplinatória; ii) ingênuaimobilista; iii) conteudista-racionalista; iv) crítica-transformadora.

Contudo, no caso de uma concepção de pesquisa crítica-transformadora, que é a adotada para essa investigação, a pesquisa-ação participativa ${ }^{3}$ (para enfatizar o caráter participativo) tem sido apresentada por especialistas (TOZONI-REIS, 2006; TOLEDO e JACOBI, 2013) como uma metodologia bastante pertinente na investigação de

${ }^{3}$ Há diversas modalidades de pesquisa-ação sendo que outros termos são adicionados ao vocábulo, dependendo da intencionalidade, da natureza da intervenção: participante; participativa; integral; sistêmica; colaborativa; comunicacional; existencial; educacional; crítico-colaborativa; emancipatória. 
fenômenos socioambientais, uma vez que apresenta coerência entre os métodos de investigação de âmbito educativo e os propósitos da educação ambiental, ou seja, o ato investigativo está comprometido, profundamente, com o ato educativo crítico, transformador e emancipatório.

Para Tozoni-Reis (2008), o fenômeno educativo é investigado no próprio processo de educar e ao se tornarem participantes de um projeto de Educação Ambiental deixam de ser "objetos" de pesquisa para se realizarem como "sujeitos". Segundo Brandão (2005), a pesquisa-ação participativa é um processo que envolve a "realidade concreta da vida cotidiana" em processos educativos coletivos e sociais.

Cabe destacar que pesquisa-ação participativa não tem o intuito de "levar consciência" ao grupo de jovens em situação de exclusão, mas de problematizar a realidade, segundo orientações de Loureiro (2007, p.35).

\section{LOCAL E SUJEITOS DA PESQUISA}

A pesquisa foi desenvolvida na região de São Domingos no município de Sumaré, que se situa na região Metropolitana de Campinas. A região é constituída de vários bairros e tem grandes problemas ligados a questões de moradias, assim como as ocupações irregulares de espaços caracterizados como bairros informais e favelas. A grande maioria das residências é precária, situada em lugares ilegais, inadequados e perigosos, como áreas de proteção ambiental, beira de rios, sempre sujeitos às instabilidades e/ou ao despejo e vulnerabilidades climáticas.

A investigação foi realizada na Unidade III da ONG Instituto Bem querer, onde acontece o Programa de Serviço de Convivência e Fortalecimento de Vínculo. Ao todo, se considerarmos todos os passos da pesquisa, tivemos a participação de 45 jovens com idade variando de 13 a 18 anos, sendo a maioria entre 15 e 16 anos. A maior parte das famílias dos jovens atendidos tem a mãe como chefe de família. Constatamos que todos frequentavam a escola, mas a maioria cursava o Ensino Fundamental II. A pesquisa foi realizada durante o segundo semestre de 2014 e o primeiro semestre de 2015.

As atividades foram realizadas com encontros semanais e em três etapas: A primeira etapa envolveu o reconhecimento da área, mediante uma saída a campo no entorno e localidades próximas ao IBQ. Esse reconhecer, para muitos jovens, era “conhecer”, pois não conheciam o entorno, assim como os bairros próximos à ONG. $\mathrm{O}$ 
passeio às proximidades do IBQ foi realizado por meio de caminhadas e registrado por meio de fotografias. Suas falas foram gravadas e/ou registradas em um diário de campo. No texto, os nomes dos jovens foram omitidos utilizando-se somente as suas iniciais, a idade e a série em que estão matriculados.

A segunda etapa foi a elaboração dos mapas dos bairros. Para tanto, utilizamos pedaços de feltro de várias cores que foram sendo colados num tecido maior, também de feltro, que serviu como uma grande tela. O grupo foi dividido em subgrupos, respeitando-se o local da moradia de cada um. Devido às dificuldades dos adolescentes quanto à orientação espacial e geográfica, foi utilizada a ferramenta do Google Maps, que possibilitou maior visualização do local facilitando a construção do mapa de cada bairro, com os destaques feitos por cada grupo. Na terceira etapa, os participantes reuniram os mapas de cada bairro para a confecção do mapa da região e também deram início à demarcação dos elementos escolhidos por eles para constarem do mapa, tais como, a via férrea, igrejas, escolas, rodoviária, caixa d'água, ribeirão, campo de futebol, posto de saúde, entre outros.

Muitos relutavam em colocar as suas casas, envergonhados por morarem em favelas. Percebia-se a preocupação de alguns em deixar claro que não moravam em uma favela. Relatos durante a realização do mapeamento explicam essa preocupação, uma vez que os moradores das favelas são discriminados pelos próprios moradores dos bairros circunvizinhos e assim, duplamente excluídos. As discussões e os debates foram registrados em um caderno de campo e gravados em áudio. Paralelamente com a elaboração do mapa, foram realizadas algumas oficinas com temas destacados por eles, tais como o lixo e a escassez de água vivenciada na região de São Paulo, que ocorreu no período.

\section{RESULTADOS E DISCUSSÃO}

$\mathrm{Na}$ construção do mapa, à medida que os elementos mais significativos dos bairros foram sendo revelados, os jovens foram sendo incentivados a investigar outros aspectos não abordados no levantamento inicial, aprendendo a reler o ambiente.

As escolas foram escolhidas pelos grupos para constarem do mapa. Alguns depoimentos apontam para a desvalorização da instituição e para situações de violência. 
Professores que gritam, professores "grossos" que não explicam, alunos "bagunceiros" são queixas dos adolescentes.

\begin{abstract}
Algumas ignorâncias dos professores quando vai (sic) explicar as matérias é o que mais me irrita...Eu gosto de estudar não ligo para bens materiais, ligo para matérias, sou de boa. Os professores não explicam, gritam o tempo todo!! (M.L. 16 anos, $2^{\circ}$ EM).

Moro na Vila Soma lá tem muitas festas e passeatas e o ponto negativo é o morro e não tem asfalto. Algo que não gosto são os professores grossos e não explicam e os alunos bagunceiros e com mau comportamento". (S. 15 anos, $\left.1^{\circ} \mathrm{EM}\right)$
\end{abstract}

Por outro lado, o docente, em geral, é agredido física e psicologicamente no dia a dia na escola, devido aos baixos salários, ao desrespeito dos alunos, à desvalorização da carreira de professor.

Pelo relato dos alunos, as escolas por eles frequentadas (em geral, longe de suas moradias) não os auxiliam no entendimento de seus direitos e nas possibilidades de qualificação. Em geral, sofrem preconceitos por serem moradores de áreas ocupadas e de invasão. Relatam não ter nenhuma discussão/orientação sobre a continuidade dos estudos. Ignoravam o significado de Prouni.

Eu quero sim fazer alguma coisa depois que terminar o ensino médio, minha mãe quer que eu faça faculdade, não sei o que quero fazer [...] Prouni, não sei o que é isto, os professores não falam nada com a gente. (Le. 16 anos $2^{\circ} \mathrm{EM}$ )

E de todo o grupo, apenas uma manifestou ter interesses já definidos com relação à Universidade, tendo já definido o curso e estratégias de estudo para alcançar esse objetivo. A jovem, moradora de umas das áreas ocupadas, teve a oportunidade de participar de um grupo de atletismo e isso lhe deu esperanças de trilhar outros caminhos.

Eu gosto muito de estudar, quando consegui a bolsa para ir para o Network fiquei muito feliz, pois não vejo a hora de fazer faculdade (TW, 18 anos, $3^{\circ}$ EM)

A presença da escola na vida desta jovem é diversa da grande maioria dos jovens que frequenta a ONG. Para a maioria, a escola representa somente um local de encontro com outros colegas, sem nenhuma perspectiva de futuro ou mesmo motivação. A baixa qualidade de ensino dificulta sonhar com uma capacitação profissional.

Eu queria muito trabalhar, mas o pessoal da escola falou que o ano que vem lá será período integral, e terei muito mais oportunidade para o meu futuro, 
além de poder me profissionalizar, posso me preparar para a faculdade. (M.16 anos, $\left.1^{\circ} \mathrm{EM}\right)$

Queria poder fazer um curso técnico e depois faculdade, mas não sei como. Eu sei que vocês falaram das faculdades que tem aqui em Sumaré, mas será que consigo entrar? (M.L. 17 anos, $2^{\circ} \mathrm{EM}$ )

Alguns alunos relutaram em demarcar locais no mapa, pois consideravam o seu bairro feio e sujo.

Não tem muita coisa para mostrar aqui no bairro, as ruas são sujas, tem muita igreja e bar. As pessoas jogam as coisas em qualquer lugar da rua, sempre tem lixo e entulho em algum lugar. (B. 14 anos. $8^{\mathrm{a}}$ EFII)

Os adolescentes também contaram algumas histórias locais, além do tráfico de drogas, das brigas, e da violência do local, uma vez já presenciaram assassinato na comunidade. Apesar dos riscos, mesmo assim, alguns consideram o bairro bom para se morar.

No meu bairro são poucas as coisas boas, para mim o bom são as amizades, comércios que são pertos, o melhor é quando nós mulheres vizinhas se juntamos e sentamos pra bater um papo, são muitas risadas [...] mas tirando essas coisas ruins é um bairro bom para morar, eu não mudaria do meu bairro. (L. 15 anos. $1^{\circ} \mathrm{EM}$ )

Eles não têm referências ambientais uma vez que tudo é ruim, mas fazem destaque para as amizades, para os bate-papos, para as risadas.

Segundo outra adolescente,

Eu moro na Vila Soma, lá é uma invasão, nós lutamos para ganhar as terras, já tivemos muitas lutas e vamos continuar lutando pelo direito a moradia. Eu gosto do lugar que eu moro apesar de não ter luz, água e esgoto eu conheço muita gente, me dou bem com todos, tenho bons vizinhos, nos ajudamos e convivemos bem. (A. 17 anos, $9^{\circ} \mathrm{EF}$ )

Não existe nada positivo no meu bairro, só tem pontos negativos como: lixo na rua, no rio e a água tem um gosto muito ruim [...]. O que mais me irrita na escola que estudo é o meio ambiente e o banheiro é um lixo. (Ma. 17 anos, $2^{\circ}$ EM)

Uma das questões levantadas pelo grupo foi a o problema da água, a falta de água e os problemas do sistema Cantareira. As discussões giravam em torno de como é o acesso à água nestas comunidades, se havia falta de água, por que estávamos no auge 
da crise de abastecimento e do drama vivenciado pelas cidades da região de Campinas que captavam a água de rios que faziam parte do sistema Cantareira, abastecidas pela Sabesp. Aprofundar o assunto era importante pela crise e pertinente, principalmente por que um dos grupos apresentou em seu bairro uma caixa d'água como destaque.

Mas ao fazer perguntas se eles tinham problemas de abastecimento de água, a resposta foi surpreendente, pois grande parte deles não tinha acesso à água. Por estarem em locais irregulares, tal como a Vila Soma, não tinham saneamento básico e oferta de água. Tinham que comprar água e gastavam em média $\mathrm{R} \$ 30,00$ (trinta reais) por semana, lembrando que a água era para higiene pessoal, para lavar roupas, preparar alimentos, ou seja, para todas as atividades domésticas e necessidades individuais.

Esse relato possibilitou conhecer mais a comunidade e o seu dia a dia, pois nem todos os adolescentes tinham esta informação. Outros adolescentes ficaram curiosos para saber mais sobre esse bairro, a Vila Soma. Por ser uma ocupação recente no município, e por apresentar algumas restrições de acesso, quase nada sabiam sobre esse local e suas particularidades.

Os jovens relatam que a água é comprada e quem organiza a compra é a associação de moradores, ou seja, os dirigentes passam de casa em casa perguntando se a família vai querer ou não água. Os moradores não podem comprar água de outra procedência, apenas em pequenas quantidades, pois só o caminhão pipa autorizado pela associação pode entrar no local. Como a sede da associação fica na entrada do bairro é possível controlar quem entra e quem sai do lugar.

Outros adolescentes apresentaram situações diferenciadas. Por exemplo, quem mora na favela da Vila Vale, tem acesso à água, porém não paga nada por ela, pois a captação de água é diretamente ligada à rede da rua, uma ligação direta, sem registro, clandestina. A conta de água, por vezes usadas em atividades na escola, para esses adolescentes não faz sentido; falar em valores do custo da água não faz parte do seu cotidiano, pois não tem ideias sobre o valor do metro cúbico da água, ou qual é o consumo mensal da família. Economia de água também não era algo significativo a eles. Ligações clandestinas são comuns.

Eu não sabia que estava faltando água aqui em Sumaré, não tem faltado água em casa [...] nós não pagamos conta de água, ela é ligada direto da rua, do encanamento. (Ca. 16 anos, $7^{\circ}$ ano) 
No entanto, outros moradores em residências ligadas à rede, apresentaram as contas de água mostrando que gastam em média cerca de $\mathrm{R} \$ 40,00$ (quarenta reais) mensais. Um custo alto mediante os baixos salários recebidos pelos pais.

De forma contraditória, o grupo social em piores condições financeiras e de moradia não tem acesso à água de torneira, fornecida pelo poder público, tendo que comprar água engarrafada, inclusive para higiene pessoal. Desprovido de condições mínimas de moradia, sem emprego, sem bens materiais, vivendo de bicos, o grupo tem que dispor do pouco que tem para sobreviver, pagando um custo alto por um bem comum.

Essa diversidade de situações permitiu que se problematizasse a realidade em relação ao tema água, em especial a (in)disponibilidade de água e a desigual distribuição entre os seres humanos, as implicações para a saúde da água contaminada, de rios, minas e bicas d'água.

Em geral, os dados sobre a água potável são alarmantes, mas no momento do encaminhamento das discussões e projetos de EA sobre a água, os educadores ambientais/professores ficam nas ações pessoais de redução de consumo, na defesa de um olhar respeitoso, ético para com a água. Não se problematiza a realidade, tampouco se permite uma mobilização coletiva que interfira em espaços e políticas públicas. Ações válidas e necessárias, mas insuficientes e reducionistas. (LAYRARGUES, 2006 e LOUREIRO, 2010)

Nos encontros seguintes demos continuidade ao mapeamento ambiental. Uma incorporação importante ao mapa, feita por todos os grupos, foi o Ribeirão Quilombo, que corta a cidade de Sumaré. Esse rio faz parte do trajeto diário de todos esses adolescentes, mas é ignorado por eles. Ao representá-lo no mapa, a discussão foi sobre a cor do feltro que deveria ser escolhida. Alguns alunos tinham dificuldades em chamar o ribeirão de "rio", pois o denominavam "esgoto". Alguns adolescentes, que moram há mais tempo na região, relataram aos colegas que seus avôs e avós brincavam no ribeirão, pescavam. Mas a maioria, como veio de fora, não tinha nenhuma relação com o ribeirão, a não ser que era um esgoto e que cheirava muito mal.

Qual seria a cor do feltro para representar as águas do ribeirão, perguntou a pesquisadora? Os jovens pareciam surpresos, pois sem dúvidas, o rio seria da cor marrom escuro! Essa era a cor que viam e a cor retratada nas fotografias. Como se a cor 
das águas do rio fosse naturalmente marrom! Observa-se a situação descrita por Meyer (1991) sobre a naturalização dos problemas. O ambiente passa despercebido, pois as pessoas se acostumam a olhar e a conviver, sem refletir, sem questionar, como se aquela realidade fosse natural em vez de uma realidade socialmente construída. A nossa capacidade de observação, de registro, de indignação, fica adormecida diante do que nos parece natural.

Outra questão é por que o rio cheira mal. É normal um rio cheirar mal? Alguém já sentiu o cheiro de um rio com águas límpidas? O que fazer para que o rio não cheire mal? Foram provocações feitas aos adolescentes. Um deles assim se posiciona:

[...] porque o povo é porco e o rio, a prefeitura não cuida, assim como a água que é horrível... (B. 14 anos, $8^{\circ} \mathrm{EF}$ )

Eles acabam relacionando o cheiro ao esgoto jogado diretamente nele, assim como o esgoto de algumas indústrias, também pela falta de planejamento das cidades e fiscalização dos órgãos ambientais, a falta de mata ciliar. O rio acaba sendo um grande lixão para a população, pois os lixos que são jogados nele, as águas levam para longe, nas palavras de um jovem. Assim, móveis, animais mortos, lixo orgânico são despejados nos rios que cortam as cidades, sem a mínima reflexão. Para a urbanista Linda Cox (2016, apud Lores, 2016, p.6) "a pior morte de um rio é quando ele parece invisível e os moradores da cidade não esperam nada de bom vindo dele”.

Os meios de comunicação- televisão e jornais- divulgam os problemas ambientais, locais e globais. Mas sempre de forma parcial e com ênfase no espetáculo, em geral, noticiando alguma desgraça, de forma dramática, tais como deslizamentos, mortes, enchentes, falta de água. Silva (2005), ao analisar notícias sobre meio ambiente em jornais de circulação nacional, concluiu que os aspectos negativos eram os mais enfatizados e restringiam-se aos aspectos factuais (imediatos) dos assuntos noticiados, sem preocupação com uma maior contextualização.

Em Sumaré, a situação não é diferente. O Ribeirão Quilombo é o centro das atenções somente no caso de enchentes, com pessoas perdendo os poucos pertences, fato que se repete ano a ano. O aumento de casos de dengue na região também foi noticiado recentemente pela mídia.

O lixo aparece como um problema dos bairros, pois a coleta não é regular pelo fato de alguns bairros ficarem em área de ocupação e também pela dificuldade de 
acesso. Há lixo por toda a parte, mas isso parece incomodar algumas adolescentes, o que pode ser observado em algumas falas.

Eu moro no bairro Vila Vale, o que eu acho ruim la são muitas coisas como o jeito como as pessoas vivem, sem respeito uns pelos outros, e pelo lugar onde sempre estão. Por exemplo, como moro em uma favela e lá tem muitas pessoas, elas jogam lixos nos becos e somos obrigadas a conviver com muita coisa errada. (Lr. 17 anos, $\left.2^{\circ} \mathrm{EM}\right)$

Gosto do meu bairro, pois tem tudo perto, mercado, padaria, sorveteria e não falta água (temos ligação direta, não pagamos por ela). O que mais me incomoda no meu bairro é o lixo, o bar e as ruas. (M.L. 16 anos, $2^{\circ} \mathrm{EM}$ )

Esses e outros assuntos destacados durante a construção do mapeamento foram retomados nas discussões em grupos, interação teoria e prática com questões do cotidiano desses jovens, nos espaços que representam a sua comunidade.

O lixo também foi um dos temas das oficinas realizados com os jovens, palavra muito presente nas falas, nas fotografias tiradas por eles e no ambiente da comunidade. Desta forma foi inevitável tratar esse tema. O tema da oficina foi: O lixo na cidade.

Queríamos nesta oficina, além de lhes dar outro olhar sobre o lixo, destacar alguns problemas trazidos durante a construção do mapeamento, como a questão da coleta pelo poder público. Na região de São Domingos, em alguns locais, há uma dificuldade enorme desse serviço. As vias de acesso às favelas são vielas, assim os moradores têm que deslocar até a rua mais próxima na qual existe uma lixeira coletiva para o descarte, pois apenas nesses locais há coleta pelo poder público.

Em alguns casos, em que as casas da favela são próximas da beira de córregos, esses acabam sendo alvo dos moradores pela facilidade de acesso. Na Vila Soma, as dificuldades são maiores, pois nesse caso os moradores têm que se deslocar até a entrada do bairro, sendo esse o único lugar de coleta de lixo realizado pelo poder publico, e ainda assim, com baixa periodicidade, uma vez na semana.

Uma das jovens destaca o problema da falta de coleta sistemática de lixo pela prefeitura.

O que eu mais queria lá no Soma é que o caminhão de lixo entrasse lá. Tem muito lixo no bairro, é muito difícil para quem mora lá em baixo levar até a entrada do Soma, muitos jogam em qualquer lugar ou botam fogo. (E. 14 anos, $6^{\circ}$ ano). 
O fato da vila Soma ser uma ocupação irregular, não significa, a nosso ver, que a prefeitura possa abrir mão de resolver o problema do lixo, pois a questão de saúde pública deveria ser colocada em primeiro lugar. As doenças transmitidas por mosquitos e por outros vetores têm altos custos para a sociedade e impactos econômicos para o Sistema Único de Saúde (SUS).

A falta de moradia adequada, de saneamento básico, de alimentação adequada, de coleta de lixo, trazem consequências desproporcionais a esse grupo de pessoas uma vez que estas correm um maior risco de terem problemas de saúde, ou seja, de sofrerem consequências ambientais negativas maiores que outros grupos, numa clara situação de injustiça ambiental.

O lixo é algo presente no cotidiano desses jovens e ao trabalharmos estas questões identificamos que alguns dos problemas estão vinculados às questões públicas, ou melhor, da ausência do poder público. E por mais que lá existam moradores que são catadores de material reciclado, a falta de planejamento, de infraestrutura na cidade, é realidade na vida desses jovens.

No caso dos catadores, esses procuram adquirir materiais mais fáceis de serem comercializados e de maior valor, como latas de alumínio, metais, pets e em geral, esses materiais não são encontrados no lixo da favela.

A questão da saúde também foi tema de discussão entre o grupo. Quando uma peça de feltro foi colada no mapa, representando o posto de saúde do bairro, todos os participantes receberam a informação que muitos jovens, não conhecem o posto de referência da sua região. Como o local de moradia de muitos deles não é legalizado, eles não detêm um endereço para que possam ser atendidos naquele posto. Isso dificulta o atendimento médico, pois os moradores têm que de deslocar para locais mais distantes. O que torna essa situação ainda mais problemática é a falta de transporte. Pelo mesmo motivo relatado acima, as linhas de ônibus não são em número suficiente para atender a região, pois aquelas pessoas "oficialmente" não existem.

Quando a gente está mal, quando dá vamos no UPA é longe e nem sempre temos condições de ir [...] só quando estamos muito mal minha mãe pede carona para alguém levar a gente, mas não gosto de ir lá, demora muito e os médicos nem olham na nossa cara. (E, 16 anos, $\left.1^{\circ} \mathrm{EM}\right)$ 
É muito comum os moradores recorrerem ao UPA (Unidade de Pronto Atendimento), que fica distante dos bairros onde moram. Os jovens relatam esse fato com naturalidade, como se aceitassem essa situação. É uma conformidade do problema, uma naturalização. E os profissionais da área de saúde não lhe darem nenhuma atenção também faz parte da rotina.

Esses mesmos jovens relataram que a energia elétrica é obtida por meio clandestino. A maioria dos pais não tem um emprego, vivendo de pequenos "bicos". A falta de moradia, de transporte coletivo adequado e a incapacidade de arcar com as tarifas dos serviços dificultam a busca e a manutenção de um trabalho. Essas e outras situações foram relatadas, e assuntos ligados às ocupações e invasões, problemas socioambientais, condições de vida das pessoas foram discutidos e analisados pelo grupo.

Um das questões levantadas foi o direito a moradia. Alguns jovens se mostraram favoráveis às ocupações, enquanto que outros, que moram casa alugadas, questionaram: Por que uns têm que pagar pela moradia e outros não?

Para mim deixaria as famílias lá, pois era um lugar abandonado não tinha nada lá e aquelas famílias vão para onde? Elas precisam de um lugar para morar. Não vejo nenhum problema elas continuarem lá. (M.L. 17 anos, $\left.2^{\circ} \mathrm{EM}\right)$

Ah! É muito complicado, pois tem um monte de gente querendo uma casa para morar, minha mãe paga aluguel e nós também queremos uma casa própria [...] será que na seleção tem só gente que precisa mesmo de casa? Lá na ocupação tem gente que já tem casa! (M. 16 anos, $\left.1^{\circ} \mathrm{EM}\right)$

Segundo Osório (s.d) "o direito humano à moradia é um dos direitos sociais assegurados constitucionalmente, no artigo $6^{\circ}$. Entretanto, mais de 6 milhões de brasileiros não têm acesso a uma moradia digna". A justiça ambiental passa por moradias dignas, em locais que não apresentem riscos a seus moradores.

Mas, segundo alguns jovens, a remoção das famílias das áreas de risco para os conjuntos habitacionais nem sempre melhora a qualidade de vida das pessoas.

Eu não acho que melhorou, não tem a ver com a moradia é que antes era só uma favela, agora eles pegaram um monte de favelas do município e colocaram todas juntas nos "predinhos". Eu acho que ficou pior. (M.L. 16 $\left.\operatorname{anos} 2^{\circ} \mathrm{EM}\right)$

Nós chamamos os "predinhos" de favelas por causa das pessoas, favelado sempre favelado, a pessoa acostuma com a vida que leva. Eles só mudaram de local, o modo de vida continua o mesmo, são briguentos, barraqueiros, 
música alta....nossa e sem falar que fica no fim do mundo e longe de tudo...eu acho que eles deveriam organizar melhor a mudança dessas pessoas.(L. 17 anos, $\left.2^{\circ} \mathrm{EM}\right)$ (grifos nossos)

A fala de L. mostra o preconceito com os favelados, que é a mesma de parte da sociedade e dos políticos.

[...] os pobres são vistos como folgados, preguiçosos, sujos, além de viverem no mundo da violência e da droga. Esses preconceitos limitam necessariamente as ações e a mobilização da sociedade civil. (SAGLIOYATZIMIRSKY, 2006, p.127)

Segundo alguns jovens, moradores da favela Vila Valle, eles seriam os últimos a serem removidos pelo fato de o local não ser considerado como área de risco pela prefeitura.

Nós não vamos sair da nossa casa, só vai sair quem está morando na beira do córrego ou área verde [...] eles falaram que é por causa das enchentes e nascentes, assim as casas têm que ser removidas. E onde moramos não tem esse tipo de problema (L. 17 anos, $2^{\circ} \mathrm{EM}$ )

O grupo foi convidado a falar qual seria o seu entendimento sobre área de risco.

Área de risco é quem mora perto do rio, sempre quando chove muito lá o quilombo enche e entra nas casas [...] principalmente quem mora na primeira rua. Desde que eu vim morar aqui sempre acontece isso. Mas tem gente que precisa saber onde vai construir sua casa, depois acontece uma tragédia não sabe por quê. (M. 16 anos, $\left.1^{\circ} \mathrm{EM}\right)$

Não sei se onde moro é área de risco, lá não tem enchente. (M.L. 17 anos, $\left.2^{\circ} \mathrm{EM}\right)$

A ideia de risco para eles é de perigo iminente, como enchentes, por exemplo. Para M. "área de risco é quem mora perto do rio". Sim, as áreas de riscos são áreas sujeitas a riscos naturais, como deslizamento de terra, inundações, margens de rio, ou aquelas decorrentes da ação humana, como contaminação do solo por resíduos. Mas também são áreas em vulnerabilidade social, nas quais há condições precárias de moradia e saneamento, situações de exclusão de direitos, nas quais o individuo é impossibilitado de ter acesso aos bens e serviços oferecidos pelo poder público.

Para Spink (2014) "a percepção de riscos no contexto de hierarquias de riscos é de fundamental importância para entender por que as pessoas constroem suas moradias em áreas de risco". E também fundamental, segundo a autora, para entender essa ambivalência quanto a querer sair e querer ficar nessas habitações. 
As condições de moradia na Vila Valle são muito precárias, então essa classificação da prefeitura é questionável. Esse grupo de pessoas está sofrendo uma parcela desproporcional de consequências ambientais negativas, portanto, uma situação de injustiça ambiental.

As discussões possibilitaram a reconfiguração da percepção de risco pelos jovens e isso poderá auxiliá-los, em especial os moradores da Vila Valle, a questionar o processo de seleção definido pela Secretaria de Habitação para a remoção das moradias. Isso poderá ser feito por meio da participação da população nos conselhos, na criação de associação de bairros, que são formas de participação da comunidade frente às decisões tomadas pelo poder público. Um dos princípios da justiça ambiental é justamente o "fortalecimento e favorecimento da constituição de sujeitos coletivos de direitos, isto é, de movimentos sociais e organizações populares capazes de interferirem no processo de decisão da política e da economia”. (LOUREIRO e LAYRARGUES, 2013, p.64 )

Desta forma, o mapeamento possibilitou a investigação da história do bairro, assuntos ligados às ocupações e invasões, problemas socioambientais, riscos, condições de vida das pessoas do bairro, construindo uma releitura do lugar. A construção coletiva do mapeamento permitiu novos olhares, novas perguntas, questionamentos que os levaram a repensar o seu cotidiano, a aparente normalidade do cotidiano.

\section{CONSIDERAÇÕES FINAIS}

O trabalho teve como objetivo a construção de um mapeamento ambiental de bairros atendidos pela ONG Instituto Bem Querer e, a partir dele, discutir coletivamente questões do e no cotidiano com os jovens, moradores dessas localidades, em geral, vivendo em situação irregular, excluídos dos direitos básicos assegurados pelo poder público, sem perspectivas de um futuro melhor.

Uma das questões iniciais foi pensar qual Educação Ambiental trabalhar com esses jovens excluídos? Como trabalhar as questões ambientais vivenciadas por eles? Como instrumentalizá- $\operatorname{los}^{4}$ para o enfrentamento da crise socioambiental, buscando suas causas, de acordo com Teixeira et al. (2013, p.658), "nas condições do modo de

\footnotetext{
${ }^{4}$ Instrumentalizar o sujeito seria dar-lhe as "ferramentas culturais necessárias à luta que travam diuturnamente para se libertar das condições de exploração em que vivem" (SAVIANI, 2006, apud Teixeira et al., 2013, p.658).
} 
produção atual, compreendido como determinante da crise a que está submetida a humanidade"?

Definitivamente, o caminho não poderia ser o de considerar os problemas ambientais dissociados dos conflitos sociais, pois afinal, "a crise ambiental não expressa problemas da natureza, mas problemas que se manifestavam na natureza”, segundo Loureiro e Layrargues (2013, p.68).

O intuito foi tratar as questões socioambientais dos bairros da região de São Domingos de modo a superar a educação ambiental disciplinatória, moralista, ingênua, de adestramento ambiental, ou de caráter conteudista (TOZONI-REIS, 2008) ainda muito presente nas escolas públicas, de forma a reconstruir a vida social, colocando-a em questão.

Questões como economizar água, economizar energia, jogar o lixo no lixo, diminuir o consumo, plantar árvores, temas em geral abordados pelos professores que dizem fazer educação ambiental, não fazem sentido para quem não tem casa, não tem água, não tem energia, não tem trabalho, não têm coleta de lixo, que vive em permanente situação de injustiça ambiental.

Ao reconstituirmos a vida nos bairros, levantamos questões locais que acontecem rotineiramente, mas que já estão naturalizadas para os adolescentes. E na visão de Meyer (1991) pelo fato de estarem naturalizadas, a capacidade de indignação, de percepção, não acontece de fato.

Ainda que sem nenhuma condição de moradia, como compreender o nível de tolerância desses jovens para com esses lugares? Mesmo quando relatam a falta de estrutura, se posicionam em favor do seu bairro "tirando essas coisas ruins é um bairro bom para morar, eu não mudaria do meu bairro", "eu gosto do lugar onde moro apesar de não ter luz, água e esgoto", "O que gosto no meu bairro são as minhas amizades (...). O que me incomoda é que não tem asfalto, não tem lixeira e às vezes algumas discussões entre bandidos". Criticam os predinhos para onde são levados: "não tem a ver com a moradia!

Os jovens parecem ter uma identidade com o lugar. Segundo Hubbard e Kitchin (2011, apud Spink, 2014, p.3751), para muitos geógrafos, o lugar representa um tipo peculiar de espaço:

[...] que é definido e construído em termos das experiências vividas das pessoas. Como tal, os lugares são vistos como fundamentais na expressão de 
um senso de pertença para aqueles que nele habitam, e são vistos como provedores de um lócus de identidade.

Por isso, Vieira (2004, p.146) considera que "é mais provável reduzir o risco mudando-se o uso do solo, ou a forma de adaptação, do que mudando de lugar". De qualquer forma, para Loureiro (2004, p.133) o importante é sensibilizar as pessoas e alterar comportamentos individuais, mas não ficar só nesse plano, é preciso "articular a cotidianidade ao macrossocial, em uma atuação política que gere as transformações individuais e coletivas, simultaneamente, e a possibilidade de as experiências localizadas que foram bem-sucedidas se universalizarem".

Essas pessoas que ocupam áreas de preservação, áreas em litígio, excluídas dos serviços públicos essenciais, sem emprego e sem perspectivas de melhoria, mostram a face atual do capitalismo, que passa, neste começo de século, da exploração à incapacidade de explorar a força de trabalho. Os custos socioeconômicos oriundos dessa situação de exclusão de milhares de brasileiros são inaceitáveis para uma sociedade que se pretende justa e sustentável.

\section{REFERÊNCIAS}

BRANDÃO, C. R. Pesquisa participante. In: FERRARO JÚNIOR, Luiz Antonio (Coord.). Encontros e caminhos: formação de educadoras(es) ambientais e coletivos educadores. Brasília: MMA/Diretoria de Educação Ambiental, 2005, p. 259-266.

LAYRARGUES, Philippe Pomier. Muito além da natureza: educação ambiental e reprodução social. In LOUREIRO, C.F.B.; LAYRARGUES, P.P.; CASTRO, R.S.de (orgs.). Pensamento complexo, dialética e educação ambiental. São Paulo: Cortez, 2006, p. 71-103.

LORES, R. J. Levar moradores ao rio poluído conquista aliados. Entrevista Linda Cox. Folha de São Paulo. Cotidiano B6, 01 de outubro de 2016.

LOUREIRO, C.F.B. Premissas teóricas para uma educação ambiental transformadora. Ambiente e Educação, Rio Grande, 8: 37-54, 2003.

LOUREIRO, C. F. B. Trajetória e Fundamentos da Educação Ambiental. São Paulo: Cortez, 2004.

LOUREIRO, C.F.B. Pesquisa-ação participante e Educação Ambiental. Uma abordagem dialética e emancipatória. In: TOZONI-REIS, M. F. de C. (Org.). A pesquisa-ação participativa em educação ambiental: reflexões teóricas. São Paulo: Annablume; Fapesp; Botucatu: Fundibio, 2007.

LOUREIRO, C.F.B. Crítica ao Teoricismo e ao Praticismo na Educação Ambiental. In: CABRAL NETO et al. (orgs). Educação ambiental: caminhos traçados, debates políticos e práticas escolares. Brasília: Liber Livro, 2010. 
LOUREIRO, C. F. B.; LAYRARGUES, P. P. Ecologia política, justiça e educação ambiental crítica: perspectivas de aliança contra-hegemônica. Trab. educ. saúde, v. 11, n. 1, p. 53-71, 2013.

MÉSZÁROS, I. A educação para além do capital. São Paulo: Boitempo, 2005.

MEYER, M. A. A. Educação Ambiental: uma proposta pedagógica. Em aberto. Brasília, v.10, n 49, p 40-45, jan. - mar. 1991.

OSÓRIO, L. Direito a moradia no Brasil. Versão eletrônica, sem paginação, s.d.

Disponível em:

file:///F:/Mestrado/Submiss\%C3\%A3o\%20de\%20artigos/Direito_a_Moradia_no_Brasil .pdf, acesso em 31/08/2016

SAGLIO -YATZIMIRSKY, M. C. A comida dos favelados. Estudos avançados, 20 (58), 2006.

SILVA, M. S. Mídia e meio ambiente: uma análise da cobertura ambiental em três dos maiores jornais do Brasil. Dissertação (mestrado em Comunicação e Cultura). Universidade Federal do Rio de Janeiro -UFRJ. Rio de Janeiro, 2005.

SPINK, M. J. Pesquisando no cotidiano: recuperando memórias de pesquisa em psicologia social. Psicologia \& Sociedade; 19 (1): 7-14; jan/abr. 2007.

SPINK, M. J. Viver em áreas de risco: tensões entre gestão de desastres ambientais e os sentidos de risco no cotidiano. Ciência \& Saúde Coletiva, 19(9):3743-3754, 2014. TEIXEIRA, Lucas André; TALAMONI, Jandira Líria Biscalquini; TOZONI-REIS, Marília Freitas de Campos. A relação teoria e prática em projetos de educação ambiental desenvolvidos em um bairro de Bauru, SP, Brasil. Ciência \& Educação, Bauru, v. 19, n. 03, set. 2013.

TOLEDO, Renata Ferraz, JACOBI, Pedro Roberto. Pesquisa-ação e educação: compartilhando princípios na construção de conhecimentos e no fortalecimento comunitário para o enfrentamento de problemas. Educação e Sociedade. v. 34, n. 122, p. 155-173, jan.-mar. 2013.

TOZONI-REIS, M. F. C. Temas ambientais como "temas geradores": contribuições para uma metodologia educativa ambiental crítica, transformadora e emancipatória. Educação em Revista, n. 27, p. 93-110, 2006.

TOZONI-REIS, M. F. C. Pesquisa-ação em Educação Ambiental. Pesquisa em Educação Ambiental, vol. 3, n. 1, p. 155-169, 2008.

VIEIRA R. Um olhar sobre a paisagem e o lugar como expressão do comportamento frente ao risco de deslizamento. Tese (Doutorado), Centro de Filosofia e Ciências Humanas, Departamento de Geociências, Doutorado em Geografia, Universidade Federal de Santa Catarina. Florianópolis, 2004. 